\title{
Author Correction: Room-temperature valley coherence in a polaritonic system
}

\author{
L. Qiu (1) ${ }^{1,2}$, C. Chakraborty ${ }^{2,3}$, S. Dhara ${ }^{4}$ \& A.N. Vamivakas (1) ${ }^{1,2 \star}$
}

Correction to: Nature Communications https://doi.org/10.1038/s41467-019-09490-6, published online 03 April 2019.

The original version of this Article omitted the following from the end of the Acknowledgements: 'This work was supported by NSF EAGER: 1836566, NSF EFRI EFMA-1542707, NSF CAREER DMR 1553788, AFOSR FA9550-19-1-0074, the Cornell Center for Materials Research with funding from the NSF MRSEC program (DMR- 1719875) and the University of Rochester University Research Award and the Leonard Mandel Faculty Fellowship in Quantum Optics'. This has now been corrected in both the PDF and HTML versions of the Article.

Published online: 27 September 2019

\begin{abstract}
(c) (i) Open Access This article is licensed under a Creative Commons Attribution 4.0 International License, which permits use, sharing, adaptation, distribution and reproduction in any medium or format, as long as you give appropriate credit to the original author(s) and the source, provide a link to the Creative Commons license, and indicate if changes were made. The images or other third party material in this article are included in the article's Creative Commons license, unless indicated otherwise in a credit line to the material. If material is not included in the article's Creative Commons license and your intended use is not permitted by statutory regulation or exceeds the permitted use, you will need to obtain permission directly from the copyright holder. To view a copy of this license, visit http://creativecommons.org/licenses/by/4.0/.
\end{abstract}

(C) The Author(s) 2019

\footnotetext{
${ }^{1}$ The Institute of Optics, University of Rochester, Rochester, NY 14627, USA. ${ }^{2}$ Center for Coherence \& Quantum Optics, University of Rochester, Rochester, NY 14627, USA. ${ }^{3}$ Materials Science, University of Rochester, Rochester, NY 14627, USA. ${ }^{4}$ Department of Physics, Indian Institute of Technology, Kharagpur 721302, India. *email: nick.vamivakas@rochester.edu
} 